\title{
EVOLUTIONARY IDEAS AND THE NATURALIZATION OF MIND IN WILLIAM JAMES
}

\author{
Luiz Henrique Santana \\ University of Sao Paulo, Brazil \\ santana.lhc@gmail.com
}

\begin{abstract}
This paper aims to identify the Darwinian and Non-Darwinian influences upon William James's theory about the naturalization of mind presented on his book Principles of Psychology. This effort intends to include the identification of William James' original proposals to of a naturalized and scientific approach of Mind. We identified some general aspects of evolutionary ideas in William James' book on the Principles of Psychology: a) his evolutionary ideas were influenced by his readings of Charles Darwin and Herbert Spencer; b) James assimilates these influences in an original way, reconciling the generality of evolution as a natural phenomenon (inspired by Spencer-Lamarck) with the probabilistic and selective principles of Darwinian evolution; c) James departs from the philosophical problem of intentionality and mental causality to propose a natural theory for the origin of thought as a source of variability, and conscience as a selection agent and efficient cause of habits formation duringt the ontogenesis of organisms; d) James defines two processes for psychogenesis (random variation and adaptation), whose origins are phylogenetic and ontogenetic, respectively; and e) It proposes a material basis (nervous system) and a causal principle (i.e. consciousness forming habits from the selection of reflex instincts and actions) to deal with the evolutionary origin of consciousness as a biological function. We conclude that the Principles of Psychology written by William James incorporates evolutionary ideas that are not exclusively Darwinian.and that James appropriates this matrix of influences and proposes an original enterprise for psychological science, integrating a new probabilistic-selective causal principle, a psychobiological mechanic for consciousness as a unified agent and a biological function, and a comparative perspective that would allow the study of psychological functions in nonhuman animals given the factual generality of zoological evolution.
\end{abstract}

Keywords: William James, Naturalization of Mind, Darwinism, Evolution and Psychology.

${ }^{*}$ Paper presented at XXIV Biennial Conference of Human Ethology 2018, in Santiago, Chile. 


\title{
INTRODUCTION
}

\author{
"Nothing in biology makes sense except in the light of evolution"
}

(Dobzhansky, 1973, p.125)

Ever since evolutionary theory entered psychological science, very little in psychology makes sense outside evolution. Evolution changed the way we studied animal behavior, personality and psychopathologies. The Principles of Psychology (James, $1890 ; 1892$ ) were a milestone for the theoretical reflection in Psychology (Knight, 1953, Valentine, 1991; Kinouchi, 2009) and a precursor of evolutionary thought in Psychology. The importance of James' psychological ideas survived more than a century of misrepresentation and over simplification (Araujo \& Honorato, 2017, Ellsworth, 1994).

The influence of William James among theoretical Psychology of the late 19th century and early 20th century has at least two distinctive features. On one hand, it helped to test the function of mind through evolutionary fitness, as it would be explored by associationists like Edward Lee Thorndike, functionalists like Robert Yerkes, behaviorists and neobehaviorists and even in early ethological thinkers just like Konrad Lorenz (Malone, 1975; Griffiths, 2006). On the other hand, the spread of Jamesian ideas would settle an empirical quest for the solution of the mind-body problem that would divide American psychology between behaviorism versus cognitivism throughout the 20th century (Malone, 2009).

This essay analyzed the relationship between James' ideas of evolution and psychological phenomena (focusing on his central concept of consciousness), and the mechanics of his theory of psychophysical causality. As William James' evolutionary ideas were influenced by the evolutionary thinking of the nineteenth century (Kinouchi, 2006), our focus was the analysis of the Darwinian and non-Darwinian influences upon William James naturalization of mind on his Principles of Psychology (James, 1890; 1892), and to identify William James' original ideas on a naturalized approach of mind life. To do so, a terminological review of William James' book Principles of Psychology (James, 1890; 1892) was performed. We searched for Jamesian use of this list of terms: Evolution, Selection, Variation, Adaptation, Development, Flow of Thought, Consciousness, Intention and Purpose, Mental life and Self. We organized a data base with all the transcriptions of the use of those terms within the Principles.

Two fundamental questions were addressed:

1) What Darwinian and non-Darwinian ideas were present in William James Principles?

2) Which were the Jamesian original proposition for an evolutionary approach of mind's nature?

These questions were summarized into three thematic axis that synthesize Jamesian thoughts on evolution: the conditions for the Naturalization of Mind in epistemological ways, the relationship between Intention and Selection or how could a random system such as life produce a teleological system like a conscious mind; and, finally, the mechanics of Adaptation, Consciousness and Mental Causation as proposed by William James. 


\section{DARWINIAN AND NON-DARWINIAN IDEAS OF EVOLUTION IN WILLIAM JAMES}

The philosopher Daniel Dennett (Dennett, 1995) divided Darwin's legacy on evolution into two parts. The first one was about the naturalization and secularization of the mind. The second one was the algorithmic processes underneath evolution. The comprehension of both these legacies are important to understand the Darwinian influences upon William James premises and proposals. Darwin proposed an algorithm for evolution based on natural selection. Natural selection is based on processes of variation and selection (Dennett, 1995; Darwin, 1859). This algorithm explains how life could be shaped by geographical, historical and developmental variables (Bowler, 1989; 2013). About the naturalization and secularization of life, early scientific psychologists would invest their efforts on the enterprise of tracking the material basis of mind and its natural history (Danziger, 1980; Bowler, 1989; 2013).

Darwin's legacy for scientific thought was decisive to spread the possibility of a purposeless, non-intentional, and non-Aristotelian world. Evolution may have possibly grown into a established natural fact even without Darwin (see Spencer, 1855), however his argument for random variation and natural selection would settle the basis for statistical thought and population genetics decades later (see Bowler, 1989; 2013). In this ways, Darwin's natural selection, his modus operandi, were even more innovative than the idea of evolution itself, although natural selection was not an unanimously accepted process by other natural philosophers of the nineteenth century.

For William James (James, 1890; 1892), the modus operandi of evolution could be diverse, but evolution itself is a fact that establishes a new theoretical framework that must push psychology to progressively become a natural science. Even after the publication of Darwin's book on the Origin of Species, general acceptance of descent with modification as the basis for the evolutionary process was not unanimous (Bishop, 1996; Penny, 2011). There were limits to the Darwinian theory that made its acceptance limited (Thagard \& Findlay, 2009), though it did inspire strong enthusiasts that were looking for a chance to demonstrate Darwin's predictions and interpretations (Glick, 1974; Hull, 2005).

The problem of the modus operandi of evolution, mentioned by James (1890; 1892), addresses two important shortcomings in Darwin's original publication (Darwin, 1859): the challenge of substrate and the challenge of mechanism (Santana, 2015). The substrate problem deals with the material basis upon which the processes of variation and selection mentioned by Darwin would occur and which would make possible the retention of the selected characters, whereas the problem of the mechanism consists in defining how the material elements articulate and interact to generate the processes of variation and selection (Santana, 2015). These challenges refer to the following questions: where does variation and selection of characters occur (on the substrate)? And in causal terms, that is, what is the chain of biological events that evolution generates (on the mechanisms)? The gap left by Darwin with regard to the processes of heredity that should form the biological basis of evolution would only be integrated into 
a unified theory with the neo-Darwinian synthesis of the 1930s deriving from the rediscovery of Mendel's experiments on the inheritance of characters in pea specimens (Crow, 1972; Gould, 2002; Stoltzfus \& Cable, 2014).

James (1890) extends evolution as a general fact throughout the different strata of matter, inorganic and organic. In his Principles, he avoided entering the problematic on the material bases and the mechanisms of zoological evolution, although he took it by fact (James, 1890; 1892). However, we shall further note how James (1890; 1892) takes the problem of modus operandi into account when formulating his own evolutionary system to approach the evolution of mind. The evolution of the mind would be a result of interactions between the nervous system, the flow of thought, intention, and consciousness. In this way, natural phenomena would be subordinated to the causal principles of evolution as well as to its historical nature.

Above all features, consciousness would be an inherent property of nature and spread throughout life taxa (James, 1890; 1892). This generality of consciousness was based upon two possible premises. The first would be that the same atoms that take part in celestial bodies are part of animal nervous system that make consciousness and thoughts possible (James, 1890; 1892). The second premise would state the inherent feature that nature would reorganize itself without creating new essences, but this reorganization would occur in different levels of organization and complexity. This mean that, according to James $(1890 ; 1892)$ there is the mind and consciousness as we know from human inner experiences and in lower levels of mind in non-human animals, in microscopic organisms, inorganic matter and in those elementary blocks of matter that make up the cosmos (James, 1890; 1892).

Although this interpretation may seem strange to a 21st century reader, it is important to introduce a usual argument on 19th century against psychological research with other non-human organisms: the idea of discontinuity between human mind and inner experiences and what other animals do as behavior or performance (Darwin, 1872; Romanes, 1872; Ebbinghaus, 1885; Gozli, 2017). That is, instead of avoiding comparative studies in psychology by the apparent distinction of nature between human cognition and animal behavior, James considered that evidence about the generality and continuity of evolution between the inorganic and organic world is evidence for a scale of consciousness present in the natural world and - at some point psychology would demonstrate subconscious mental life in simple life forms, chemical substances and even in atoms (James, 1890; 1892).

By taking consciousness as a subject of evolution, James (1890) would need to define what this consciousness is in both humans and nonhuman animals, how it would be possible to observe and measure consciousness in other organisms and how it would act on the expression of the behavior of organisms and the causation of psychological events.

William James $(1890 ; 1892)$ treated the evolution of consciousness in strictly biological definitions and explained the origin and development of consciousness according to a Darwinian framework. Consciousness would have emerged from a completely random biological system like an ancient nervous system or even older (e.g. in unicellular organisms) and it would have evolved by the selective effect caused by the increase of the organism fitness. From here, James uses an explicitly Spencerian expression - "[...] an animal race may grow to be a better match for its environment" (James, 1890 , p. 877$)$ - to refer to the process of adaptation of the organism to unforeseen 
changes in its natural environment, and simultaneously deals with evolutionary processes by the heritability of adaptive traits derived from the process of accidental variation (Darwinian idea) and habituation and strengthening by exercise (SpencerianLamarckian idea).

The convergence of themes makes the evolutionary definitions of William James distinctive from other naturalized theories of mental life in 19th century. And the treatment he gave for the mechanics of the biological and mental processes that serve as substrates for these processes made his propositions useful for the integration between neural studies and psychological ones at the beginning of the 20th century (MonteFerreira, Nogueira \& DeFelipe, 2014). James considers the nervous system a scientific object of great interest for understanding psychological processes and neuropathologies as a source of information on psychic disorders (Alcover \& Mazo, 2012; Monte-Ferreira, Nogueira \& DeFelipe, 2014).

The nervous system (NS) is treated in the Principles as an organic system whose function is to act intelligently in order to select actions, modulate the action of instincts and drives, and create goals and intentions for self-preservation and evolutionary success. For James $(1890$; 1892), furthermore, NS would have evolved so that its peripheral portions would be specialized in performing automated and ancestral activities, whereas the brain and cerebral hemispheres would be the more recent structures and therefore would have evolved to accommodate the intellectual, cognitive, or superior functions.

It is stated in the Principles that the cerebral hemispheres would then have a fundamental role in adaptive processes and in the formation of new habits capable of changing and adjusting the behavior of organisms to the nuances of the environment (James, 1890; 1892). This adaptation process can be improved and become more efficient throughout the development of an organism - in its ontogeny - yet a significant part of the intelligent potential and stages of this development would be established from the origin of an organism by its heredity and its phylogeny (idem). This ontogeneticphylogenetic balance of James's conception of cognitive development is further evidence of James's dual conception of the evolutionary bases of cognition in which processes of random variation could generate instincts selected by the environment and maintained by heredity, just as NS could generate reflex actions on which consciousness could act in order to promote or extinguish habits. According to James (1890; 1892), the mechanics of consciousness would come out in two processes quite familiar to the conscious subject. Remembering and forgetting would be complementary processes that would reveal how consciousness produce attention so it can promote or extinguish thoughts (James, 1890; 1892). The consciousness would act as an inhibitor of instinctive actions and modulate its form and frequency to avoid errors, risks, incongruities, and exaggerations. And, as a function of Nervous System, consciousness would be a selection agent that would define what to remember, in what context to recover this memory and how to access previous experiences in order to act efficiently in a present situation (James, 1890; 1892).

In his Principles of Psychology (James, 1890; 1892), William James (1890; 1892) proposes that psychology, as a natural science, should be based on two basic evolutionary principles. A mechanism that promotes variability - as seen in the flow of thought - selection when consciousness makes efficient actions more frequent and likely to recur - and retention through learning. It is a material substrate upon which selection 
takes place, in which case the nervous system would be the promoter of mental functions and where retention of the content selected by consciousness would occur.

This Jamesian selective proposition differs from the Darwinian system. Darwin dealt with the evolution of instinct and habit by its hereditary determinants, i.e. had a closer focus on genetic than neural determinism (Jacyna, 2009). This nervous-system-centric premise in James, which includes the possibility of heritability of neural associations by their evolutionary efficiency between generations, is a direct influence of Herbert Spencer's Neo-Lamarckism (Spencer, 1855).

James also differs from Darwin $(1859,1871,1872)$ by attributing to the organism protagonism and active role in its evolution. Charles Darwin constructed his theory on the evolution of species on two premises (Darwin, 1871; Jacyna, 2009): 1) individual variation as a source of variability; and 2) environmental pressures as agents that select variants capable of surviving and reproducing in a given environment for a given period. These premises were supported by a broad set of evidence pointing to a common genealogy for life and a principle of divergence for the differentiation of living beings from the progeny with modification (Darwin, 1871). Because Darwin considers the variability of characters to happen by chance and by assigning the environment the role of selecting agent, Darwin - at the same time - places the organism as the subject of evolution and separates the object from selection (i.e. an attribute or characteristic of one or more individuals) of their product (i.e. the frequency of a biological characteristic in a given population) (Darwin, 1859).

By electing consciousness as a selection agent and thought as a source of variability, James carried the most basic algorithm of the Darwinian system into its psychological system, appropriating the logical-formal component of the Darwinian explanation (Taylor, 1990; Kinouchi, 2006). However, in epistemological terms, this same decision removes James from the probabilistic doctrine used by Darwin in his selective texts (Darwin, 1858, 1859, 1871, 1872). In focusing the selection upon consciousness, James used a model of determinism based on internal causation and upon the naturalization of intention that would accompany much of American psychology during the twentieth century (Knight, 1953; Kinouchi, 2006; Skrupkelis, 2011). This kind of determinism stems from that premise about freedom and the protoganism of the individual's actions over his own destiny and resembles the evolutionary doctrine of Herbert Spencer (cf. Roark, 2004).

\section{WILLIAM JAMES NATURALIZATION OF MIND}

James $(1890 ; 1892)$ states that the function of the instincts is to serve as a source of variability of the action of the organisms in the world and allowing the organism active action on its environment. Since each instinct will have different efficiency over the environment in regard to the self-preservation and evolutionary effectiveness of an organism, these instincts could be modified, perfected or suppressed according to their environmental effect from the formation of habits (James, 1890; 1892). Habit forming 
would be a pattern of conduct capable of making instincts more sensitive to particular variations in the environment and efficient in generating individual advantages.

However, this habit formation would not be passive. Each organism would have an NS - according to James $(1890 ; 1892)$ - to be able to act in the world in an intelligent way.

This intelligent action would be done by the organism's active selection of the most efficient actions in a given contexts. This process of identifying goals, or intentions, and selecting efficient behaviors is what defines consciousness for William James (see James, $1890 ; 1892$ ).

Consciousness is an active filter that models behavior and modifies instinctive and reflex patterns in order to select the most efficient chain of actions to deal with a given scenario and at the same time make the occurrence of potentially disadvantageous or risky actions less frequent or likely (James, 1890; 1892).

"Consciousness consists in the comparison of these with each other, the selection of some, and the suppression of the rest by the reinforcing and inhibiting agency of attention. The highest and most elaborated mental products are filtered from the data chosen by the faculty next beneath, out of the mass offered by the faculty below that, which mass, in turn, was sifted from a still larger amount of yet simpler material, and so on. The mind, in short, works on the data it receives very much as a sculptor works on his block of stone. In a sense, the statue stood there from eternity. But there were a thousand different ones beside it, and the sculptor alone is to thank for having extricated this one from the rest. Just so the world of each of us, however different our several views of it may be, all lay embedded in the primordial chaos of sensations, which gave the mere matter to the thought of all of us indifferently".

$$
\text { (James, 1890, p. 174). }
$$

As a function of the Nervous System, consciousness would be a selection agent that would define what to remember, in what context to recover this memory and how to access previous experiences in order to act efficiently in a present situation (James, 1890). James $(1890 ; 1892)$ incorporates from the philosophical doctrine of associationism the idea of "connections" that could generate changes of attitude in form of new habits. However, James expands this concept when explaining that these processes of association would generate, in material terms, the strengthening of nerve connections in the brain and between its hemispheres. On his reasoning, James proposed that the peripheral parts of the NS are the substrates for generating reflex acts as a source of action variability whereas the cerebral hemispheres would be the material basis for consciousness as the source of intelligence and cognitive functions like attention, memory, reasoning, and language, for example.

"It is the merit of the associationist school to have seen the wide scope of these effects of neighborhood in time and space; and their exaggerated applications of the principle of mere neighborhood ought not to blind us to the excellent service it has done to

Psychology in their hands. As far as a large part of our thinking goes, then, it can intelligibly be formulated as a mere lot of habits impressed upon us from without. The degree of cohesion of our inner relations, is, in this part of our thinking, proportionate, 
in Mr. Spencer's phrase, to the degree of cohesion of the outer relations; the causes and the objects of our thought are one; and we are, in so far forth, what the materialistic evolutionists would have us altogether, mere offshoots and creatures of our environment, and naught besides.".

(James, 1890, pp. 421-422).

A distinctive feature of William James's ideas is that, by having Spencer and Darwin's influence, he could have used either of these two views on the origin of variation and their respective interpretations of the finalist nature of natural selection (Reed, 1978; Lennox, 1993; Heads, 2009). Nonetheless, James (1890; 1892) uses an original alternative to Spencer (1855) and Darwin's approach. James $(1890 ; 1892)$ derives from the organism's privileged access to his mental world to describe a random (though not random) mechanism, the flow of thought, as the object of a teleological cognitive function, consciousness.

Jamesian consciousness is a teleological function insofar as it explains the efficient causes of behavior, i.e. consciousness, as a selection agent, explains the proximal purposes of a behavior, while zoological evolution explains the ultimate causes (James, $1890 ; 1892)$. In this way, James $(1890 ; 1892)$ adapts Darwin's premises to an analysis centred on the body's individual and mental experience, focusing on the body's private world experience to explain the evolution of instincts and habits. William James proposed an evolutionary theory of emotions as an adaptive function of the organism and a theory of consciousness as a unified and intentional agent (Hart, 1981, Knight, 1953, Valentine, 1991).

By defining consciousness as an agent of selection, James uses a model of internalistintentionalist determinism that would chase much of American Psychology during the twentieth century (Knight, 1953; Danziger, 1980; Kinouchi, 2006; Skrupkelis, 2011). This intentionalist-determinism stems from the premise that consciousness, as a selection agent, explains the proximal purposes of a behavior, while zoological evolution explains the ultimate causes about the free nature and the protagonist role of the individual's actions over his own destiny and resembles the evolutionary doctrine of Herbert Spencer (Cf. Roark, 2004).

The concept of consciousness in James deals with the intentional nature of psychological phenomena (James, 1890; 1892; Kinouchi, 2006; Nielsen \& Day, 1999). As a nineteenth-century psychologist, James $(1890 ; 1892)$ developed his concepts from the epistemological and scientific debate in which psychology was shrouded during the second half of that century (Lawfor, 2006). The works of Franz Brentano (1838-1917) had a great impact on the definition of psychology as a scientific discipline and in the demarcation of its theoretical scope (Feest, 2014). Brentano defined intentionality as one of the distinguishing criteria of psychological phenomena in relation to other strictly physical events:

"Every mental phenomenon is characterized by what the Scholastics of the Middle Ages called the intentional (or mental) inexistence of an object, and what we might call, though not wholly unambiguously, reference to a content, direction toward an object (which is not to be understood here as meaning a thing), or immanent 
objectivity. Every mental phenomenon includes something as object within itself".

(Brentano, 1874, p. 88)

Brentano (1874) establishes intentionality as a criterion but does not define the concept definitively. The nature and role of intentionality in the midst of psychological phenomena will be appropriate and adapted among different authors but will remain as a distinctive criterion of psychological phenomena in analytic philosophy, phenomenology, and scientific psychology to the first decades of the 20th century (Feest, 2014). James $(1890 ; 1892)$ considers intentionality as a fundamental dimension of the mind as the object of psychology.

"And has the reader never asked himself what kind of a mental fact is his intention of saying a thing before he has said it? It is an entirely definite intention, distinct from all other intentions, an absolutely distinct state of consciousness, therefore; and yet how much of it consists of definite sensorial images, either of words or of things? Hardly anything! Linger, and the words and things come into the mind; the anticipatory intention, the divination is there no more. But as the words that replace it arrive, it welcomes them successively and calls them right if they agree with it, it rejects them and calls them wrong if they do not. If has, therefore, a nature of its own of the most positive sort, and yet what can we say about it without using words that belong to the later mental facts that replace it? The intention to-say-so-and-so is the only name it can receive. One may admit that a good third of our psychic life consists in these rapid premonitory perspective views of schemes of thought not yet articulate." (James, 1890, p. 253).

Since its foundation in the nineteenth century, scientific psychology deals with an epistemological dilemma about how to reconcile the apparent paradox between the intentional nature of psychological phenomena and the random nature of the origin of life, its evolution and variability (Brentano, 1874; Pierre, 2014). This problem was approached from different perspectives and theoretical systems in psychology and can be stated as follows: how a strictly random system such as the evolution of living organisms could have built an intentional system like the mind? Is it possible to trace a genealogy of intentionality between animal taxa? And what distinguishes the human mind from other living beings?

In general terms, the concept of intentionality consists of the power of mind to represent or establish meaning and purpose (Pierre, 2014). The problem of intentionality is particularly important to the philosophy of a psychological science as it serves as the basis for questions of an ontological nature (e.g. by the importance of intentionality to explain the mind-body problem), epistemological criteria (e.g. by its implication to the debate on the dichotomy between reductionism and holism) and methodological aspects in psychology (e.g. its impact on the definition of theoretical systems in psychology as behaviorism and cognitivism; Brentano, 1874; James, 1890; 1892; Pierre, 2014).

The intentional nature of the mind states that the actions of an organism are directed by motives or purposes (Brentano, 1874). The search for these goals and the definition of ultimate ends that would explain each behavior of an organism may seem to be 
contrary to the randomness of evolutionary theory (Ringen, 1993). In other words, if everything that a human being does has a specific function and fulfill a necessary purpose for the full functioning of reason and higher functions of the mind, how can one imagine that such a mind could have evolved from basic or rudimentary elements if its complexity is perfect and irreducible (Richards, 2003; Glickman, 2009)? As a forerunner of comparative and evolutionary studies in psychology, William James would approach this problem in his Principles of Psychology (James, 1890, 1892).

James (1890; 1892), like Darwin (1859), recognizes the intentional nature of human actions. However, it was James $(1890 ; 1892)$ who set out to postulate a principle that explained the relationship between the intentionality of human actions and the consciousness. The intentionality, for James $(1890 ; 1892)$, allows the organism to be sensitive to the effects of its actions on the environment, anticipating consequences and allowing the attribution of value to experiences.

In the Principles, intention allows us to value an experience as desirable or harmful. This process of evaluation is continuous and lasts throughout the life of the organism. However, it is only the source of subjective experiences. The body still has to select what to do, i.e. what behavior or intelligent action too, so that it can act efficiently on the environment. To do so, there must to be a specific cognitive function to select these motor actions based on the circumstantial purpose of a behavior or - ultimately - in adapting an organism's actions to the satiety of its physiological drives. Consciousness exerts this selective function (James, 1890; Kinouchi, 2006). It would act by modulating the investment of attention over a thought, making it stronger and more frequent or weaker and rarer, according to the needs and intentions of an organism.

In this way, intentionality would be a source of variation of subjective experiences, and this constant variation generates the flow of thought (James, 1890). The nature of the variability of this flow of thought, though continuous, is not strictly random. In fact, it is a product of the evolutionary history of the organism or, in other words, variation is determined by the intentionality of the motives and acts of an organism behavior (James, 1890). The non-random nature of the variability of mental experience produced by intentionality may seem to be a point of distinction between James (1890) and Darwin (1859). Yet Darwin himself recognizes human intentionality, though he does not devote himself to explaining how it might have emerged by his principles of selection of accidental variations (Darwin, 1859; Hodson, 2006). Otherwise, the Jamesian theory of intentionality seems only to offer a complement to Darwin by constructing an explanatory tool about the evolution of intentionality and mental mechanics according to evolutionary principles.

By defining consciousness as an attribute that could increase individual fitness and improve its adaptative abilities to deal with environmental contingencies by creating an intentional system, James $(1890 ; 1892)$ assimilates a transcendent idea about immanency. Immanent properties could emerge from environmental regularities just like abstract notions from real objects (Charles, 2011; Tounneau, 2011; 2013). That would be the source of the neorealist school in American philosophy and of immanentists like Edwin Bissel Holt and Edward Chace Tolman (Charles, 2011).

An immanent concept is not material or mental but is defined by the properties of environment and by abstraction (Charles, 2011; Tounneau, 2011; 2013). This abstraction would be produced by an intentional effort to associate these regularities into 
meaningful and efficient effects upon the environment (Charles, 2011; Tounneau, 2011) and would depend on "higher-order property of temporally extended environmental variables" (Tounneau, 2004, p. 99). By taking the quest of psychological science as a seek for final causes for why the mind and the self would work in such manner and to seek for the empirical proof of mental life dynamics, William James (James, 1890; 1892) designed a project for a natural science of intentionality. As the mind and self are teleological, in James $(1890 ; 1892)$ sense, their science should unveil the final causes of these functions through empirical measure and test.

\section{FINAL THOUGHTS}

Evolutionary ideas allowed the intersection of explanatory theories and models about the general functioning and history of life on earth and allowed for a great theoretical, methodological and technological development of biology in the last two centuries (Mayr, 1982; 2002; Shapiro, 2011; Losos et al., 2013). The evolutionary ideas applied to scientific psychology can bring it closer to the other natural sciences and offer an epistemological alternative that support the debate between theoretical and nonreductionist theoretical systems (Putnam, 1997). That does not eliminate Psychology as an independent science, nor does it reduce psychological phenomena to biological, chemical or physical phenomena (Putnam, 1997).

To build this bridge, it is fundamental to know the historical evolution of evolutionary theories within psychology in order to historically circumscribe which matrices of influence were important in the reception and development of evolutionary ideas within the psychological systems and to identify the epistemic and methodological biases surrounding traditional disciplines such as the Experimental Analysis of Behavior, Evolutionary Psychology, Ethology and Cognitive Psychology, for example, and to make this divergent subjects to converge to a common scope of theoretical and methodological questions.

James $(1890 ; 1892)$ sought a consistent foundation for psychological science and he treated evolution as evidence of mind's natural history and as mechanism for a physical integration between mind and nature. In this essay, we identified some general aspects of evolutionary ideas in William James' Psychology principles, namely: a) Jamesian evolutionary ideas were deeply marked by the work of Charles Darwin and Herbert Spencer; b) James assimilates these influences in an original way, reconciling the generality of evolution as a natural phenomenon (inspired by Spencer-Lamarck) with the probabilistic and selective principles of Darwinian evolution; c) James departs from the problematic about intentionality and mental causality to propose a natural theory for the origin of thought as a source of variability and consciousness as a selection agent and efficient cause of habits formation during the ontogenesis of organisms; d) James defines two processes for psychogenesis (random variation and adaptation), whose origins are phylogenetic and ontogenetic, respectively. It proposes a material basis (nervous system) and a causal principle (i.e. consciousness forming habits from the selection of reflex, instincts and actions) to deal with the evolutionary and mechanical origin of consciousness as a biological function. 
We conclude that the Principles of Psychology written by William James incorporate evolutionary ideas that are not exclusively Darwinian and that James appropriates from this matrix of influences and proposes an original scientific enterprise for psychology integrating a new probabilistic-selective causal principle, a psychobiological mechanic for consciousness as a unified agent and biological function, and a comparative perspective that would allow the study of psychological functions in nonhuman animals given the factual generality of zoological evolution.

William James (James, 1890; 1892) proposed a natural science of psychology that on one hand - accepts the intentional nature of psychological phenomena, and - on the other hand - would consider the motor and public manifestation of mind processes as a necessary feature of mental life. As for James, those two features are defining parts of a natural definition of mind and mental life, in a way that intention would be a drive for adaptation and public-motor manifestation a necessary effect that would select fittest behavior. James has to be placed outside the dichotomy of cognitive and behaviorist psychology, otherwise we would be anachronical. James - as Edwin Holt, Edward L. Thorndike, Edward Chace Tolman and others - thought psychology beyond a simple dichotomy between mind versus behavior or intention versus objectivity. James accepts intention as natural, pretty much as Darwin and Spencer. Simultaneously, James seeks for objective proof of mental life as a way to measure and test the regularities of mental processes.

In a time of extreme fragmentation of psychological knowledge, a review of past theoretical systems would light up relevant criteria of truth and proof in psychological science. As a founding father of this scientific field, review some theoretical basis of William James may help us to seek out new ways to understand, criticize and integrate data by taking into account biases and premises of psychology on its early days.

\section{FUNDING INFORMATION}

This research was partially funded by Brazil's National Council for Scientific and Technological Development $(\mathrm{CNPq})$ through a Doctoral Research Scholarship granted to the author (Process Number 142215/2016-3).

\section{REFERENCES}

Alcover, C. M. Mazo, F. R. (2012). Plasticidad Cerebral y Hábito en William James: un antecedente para La Neurociencia Social. Psychologia Latina, 3(1), 1-9.

Araújo, S. F.; Honorato, A. F. (2017). Para Além dos Princípios de Psicologia: Evolução e Sentido do Projeto Psicológico de William James. Psicologia em Pesquisa, 11(1), 5-13. DOI

Bishop, B. E. (1996). Mendel's Opposition to Evolution and to Darwin. Journal of Heredity, $87(3), 205-217$. DOI 
Bowler, P. J. (1989).The History of an Idea, revised edition. Berkeley: The University of California Press. Originally Published in 1983.

Bowler, P. J. (2013). Darwin Deleted: Imagining a World without Darwin. Chicago: The University of Chicago Press. DOI

Brentano, F. (2009). Psychology from an Empirical Standpoint. London: Routledge. First Published in 1874. DOI

Charles, E. P. (Ed.). (2011). A New Look at New Realism: The Psychology and Philosophy of E. B. Holt. New Brunswick, NJ: Transaction Publishers. DOI

Crow, J. F. (1972). Darwinian and non-Darwinian evolution. In: Procedures to the Sixth Berkeley Symposium on Mathematics, Statistics and Probability, Vol. 5, pp. 1-22. Berkeley: University of California Press.

Danziger, K. (1980). The History of Introspection Reconsidered. Journal of the History of the Behavioral Sciences, 16(3), 241-262. DOI

Darwin, C. R. (1869). On the Origin of Species by Means of Natural Selection, or the preservation of favoured races in the struggle for life, 5th edition. London: John Murray. First Published in 1859. DOI

Darwin, C. R. (1876). On the Origin of Species by Means of Natural Selection, 6th Edition. London: John Murray. First Published in 1859. DOI

Darwin, C. (1897). The Expression of the emotions in animals and men. New York: D. Appleton and Company. First Published in 1871. DOI

Dobzhansky, T. (1973). Nothing in Biology Makes Sense except in the Light of Evolution. The American Biology Teacher, 35(3), 125-129. DOI

Ebbinghaus, H. (1913). Memory: A Contribution to Experimental Psychology. New York: Columbia University Press. First Published in 1885. DOI

Ellsworth, P. C. (1994). William James and Emotion: Is a Century of Fame Worth a Century of Misunderstanding? Psychological Review, 101(2), 222-229. DOI

Feest, U. (2014). The Continuing Relevance of Nineteenth-Century Philosophy of Psychology: Brentano and the Autonomy of Psychological Methods. In: Galavotti M., Dieks D., Gonzalez W., Hartmann S., Uebel T., Weber M. (eds). New Directions in the Philosophy of Science. The Philosophy of Science in a European Perspective, vol 5. Basel: Springer International Publishing. DOI

Glick, T. F. (ed.). (1974). The Comparative Reception of Darwinism. Austin, TX: University of Texas Press.

Glickman, S. E. (2009). Charles Darwin, Alfred Russel Wallace, and the Evolution/Creation of the Human Brain And Mind. Gayana, 73, 32-41. DOI

Gould, S. J. (2002). The Structure of Evolutionary Theory. Cambridge: Belknap Press of Harvard University Press. DOI

Gozli, D. G. (2017). Behaviour versus performance: The veiled commitment of experimental psychology. Theory \& Psychology, 27(6), 741-758. DOI

Griffiths, P. E. (2006). Ethology, Sociobiology, and Evolutionary Psychology. IN: Sahotra, S.; Plutynski, A. A Companion to the Philosophy of Biology. London: Blackwell Publishing. DOI: $10.1002 / 9780470696590 . c h 21$. DOI

Hart, J. (1981). The Significance of William James' ideas for modern psychotherapy. Journal of Contemporary Psychotherapy, 12(2), 88-102. DOI

Heads, M. (2009). Darwin's changing views on evolution: from centres of origin and teleology to vicariance and incomplete lineage sorting. Journal of Biogeography, 36(6), 1018-1026. $\underline{\mathrm{DOI}}$

Himmelfarb, G. (1959). Darwin and the Darwinian Revolution. London: Chatto\&Windus. 
Hodgson, G. M. (2006), Instinct and Habit Before Reason: Comparing the Views of John Dewey, Friedrich Hayek and Thorstein Veblen. IN: Krecké, E. Krecké, C. Koppl, R. G. (ed.) Cognition and Economics (Advances in Austrian Economics, Volume 9). Wien: Emerald Group Publishing Limited, 109-143. DOI

Hull, D. L. (2005). Deconstructing Darwin: Evolutionary Theory in Context. Journal of the History of Biology, 38(1), 137-152. DOI

Jacyna, S. (2009). The most important of all the organs: Darwin on the Brain. Brain: A Journal of Neurology, 132(12), 3481-3487. DOI

James, W. (1890). The Principles of Psychology, Vol. 01. New York: Henry Holt and Company. DOI

James, W. (1892). The Principles of Psychology, Vol. 02. New York: Henry Holt and Company. DOI

Kinouchi, R. R. (2006). Darwinismo em James; A função da Consciência na Evolução. Psicologia: Teoria e Pesquisa, 22(3), 335-362. DOI

Knight, M. (1953). The Permanent Contribution of William James to Psychology. British Journal of Educational Psychology, 23(2), 77-86. DOI

Lawfor, M. S. (2006). William James's Psychological Pragmatism: Habit, Belief and Purposive Human Behavior. Cambridge Journal of Economics, 30(3), 321-345. DOI

Lennox, J. G. (1993). Darwin was a Teleologist. Biology and Philosophy, 8(4), 409-421. DOI

Levitt, M. (2013). Perceptions of Nature, Nurture and Behavior. Life Science, Society and Policy, 9(13). DOI

Losos, J. B. Arnold, S. J. Bejerano, G. Brodie, E. D. Hibbett, D. Hoekstra, H. E. Mindell, D. P. Monteiro, A. Moritz, C. Orr, H. A. Petrov, D. A. Renner, S. S. Ricklefs, R. E. Soltis, P. S. Turner, T. L. (2013). Evolutionary Biology for the 21st Century. PLoS Biology, 11(1): e1001466. DOI

Malone, J. C. (1975). William James and B. F. Skinner: Behaviorism, Reinforcement, and interest. Behaviorism, 3(2), 140-151

Malone, J. C. (2009). Radical Behaviorism and Cognitive Science: Contrasting Psychologies of the Twentieth Century? IN: Psychology: Pythagoras to Present. Cambridge, Ma: MIT Press.

Mayr, E. (1982). The Growth of Biological Thought: Diversity, Evolution, and Inheritance. Cambridge: Belknap Press of Harvard University Press.

Mayr, E. (2002). What Evolution Is. London: Phoenix.

Monte-Ferreira, F.R. Nogueira, M.I. DeFelipe, J. (2014). The influence of James and Darwin on Cajal and his research into the neuron theory and evolution of the nervous system. Frontiers in Neuroanatomy, $8(1)$. DOI

Nielsen, M. Day, R. H. (1999). William James and the Evolution of Consciousness. Journal of Theoretical and Philosophical Psychology, 19(1), 90-113. DOI

Penny, D. (2011). Darwin's Theory of Descent with Modification, versus the Biblical Tree of Life. PLOS Biology, 9(7): e1001096. DOI

Pierre, J. (2014). Intentionality. In: Zalta, E. N. (Ed.) The Stanford Encyclopedia of Philosophy (Winter 2014 ed.). Retrived in from https://plato.stanford.edu/archives/win2014/ entries/intentionality/

Pinker, Steven. (2004). Why Nature \& Nurture Won't Go Away. Daedalus 133(4): 5-17. DOI

Putnam, R. A. (1997). The Cambridge Companion to William James. Edinburgh: Cambridge University Press. DOI

Reed, E. S. (1978). Darwin's Evolutionary Philosophy: The Law of Change. Acta Biotheoretica, 27(3), 201-235. DOI 
Richards, R. J. (2003). Darwin on Mind, Morals, and Emotions. In: Hodge, J. Radick, G. (ed.). The Cambridge Companion to Darwin, 92-115. Cambridge: Cambridge University Press. DOI

Ridley, M. (2003). Nature Via Nurture: Genes, Experience, and What Makes Us Human. New York: Harper Collins.

Ringen, J. D. (1993). Adaptation, Teleology, and Selection by Consequences. Journal of the Experimental Analysis of Behavior, 60(1), 60-63. DOI

Roark, E. (2004). Herbert Spencer's Evolutionary Individualism. Quarterly Journal of Ideology, $27(3)$.

Romanes, G. J. (1882). Animal Intelligence. London: Paul K. Trench. DOI

Santana, L. H. (2015). Two challenges of a selectionist analogy to the theory of selection by consequences. PerspectivasemAnálise do Comportamento, 6(1), 40-47. DOI

Shapiro, J. A. (2011). Evolution: A View from the 21st Century. Upper Saddle River: FT Press Science.

Silverman, R. E. (2011). Is Psychology a Science? Skeptic Magazine, 17(1), 36-39.

Skrupkelis, I. K. (2007). Evolution and Pragmatism: An Unpublished Letter of William James. Transactions of the Charles S. Pierce Society: A Quarterly Journal in American Philosophy, 43(4), 745-752.

Spencer, H. (1855). Principles of Psychology, Vol. 01. 3rd edition. London: Williams and Norgate. $\underline{\mathrm{DOI}}$

Stoltzfus, A. Cable, K. (2014). Mendelian-Mutationism: The Forgotten Evolutionary Synthesis. Journal of the History of Biology, 47(4). DOI

Taylor, E. (1990). An Evolutionary Theory of Consciousness. Annals New York Academy of Science, 602(1), 7-33. DOI

Thagard, P. Findlay, S. (2009). Getting to Darwin: Obstacles to Accepting Evolution by Natural Selection. Science \& Education. DOI

Tounneau, F. (2004). Consciousness outside the head. Behavior and Philosophy, 32, 97-123.

Tounneau, F. (2011). Holt's realism: new reasons for behavior analysis. IN: Charles, E. P. (Ed.). A New Look at New Realism: The Psychology and Philosophy of E. B. Holt. New Brunswick, NJ: Transaction Publishers. DOI

Tounneau, F. (2013). Neorealism: Unifying Cognition and Environment. Review of General Psychology, 17(2), 237-242. DOI

Valentine, E. R. (1991). William James's The Principles of Psychology: 'A seemingly inexhaustible source of ideas'. British Journal of Psychology, 82(2), 217-227. DOI 